\title{
DELITOS CONTRA LA PROPIEDAD
}

\author{
JORGE TAMAYO VIERA 1
}

\section{TUNGURAFUA}

Pag 9-10

\section{Resumen}

El índice de homicidios es el reflejo de la violencia que se genera en toda sociedad y en especial en aquellos delitos que tienen que ver contra la propiedad de bienes privados, ocasionando inseguridad real y directa en la provincia de Tungurahua. Laactividad comercial, financiera, bancaria se ve afectada diariamente por la delincuencia que actúa en forma violenta bajo el consumo de alcohol y otras sustancias sujetas a fiscalización. A continuación se presenta el número de delitos cometidos en Tungurahua por robo y hurto incluyendo los delitos contra la propiedad en el primer semestre 2016 con los principales horarios en los que suelen suscitarse.

\section{Palabras clave:}

Violencia, delito, inseguridad, sociedad, intimidación

\section{Abstract}

Homicide rates are the reflection of the violence generated in any society and especially in those crimes that have to do with the vandalism of private property, which causes a real and personal sense of insecurity in the province of Tungurahua.

Commercial, financial, and banking activities are affected daily by crime. These are enacted in a violent form under the influence of alcohol and other controlled substances. In continuation the number of crimes which were registered in Tungurahua in the catagories of theft and petty theft, also including vandalism were seen as being the ones of the most commonly occurring during the first part of 2016.

\section{Keywords:}

Violence, crime, insecurity, society, intimidation

\section{Introducción}

En el contexto social de América Latina, el índice de homicidios determina la violencia, no obstante en los actuales momentos los mayores problemas que aquejan a las personas son aquellos que van en contra de la propiedad. Bajo esta consideración se puede relacionar en forma directa los delitos que atentan a la propiedad y la inseguridad real y subjetiva en la sociedad ecuatoriana. (FLACSO, Sede Ecuador)

En Tungurahua sus habitantes se dedican en su mayoría a las ferias de ganado, venta de vehículos y otras actividades comerciales que son seguidas con mucho interés por parte de personas inescrupulosas que merodean por el sector, buscando el momento propicio para dar rienda suelta a sus fechorías. Los factores que propician al cometimiento de los delitos son el consumo de alcohol, el expendio de droga, la tenencia de armas, la proliferación de libadores en vía pública, la violencia de género y delincuencia en el transporte público, entre otros.

Para dar seguimiento a estos delitos la provincia cuenta con 6 distritos de policía: Ambato Norte, Ambato Sur, Píllaro, Patate, Quero y Baños, subdivididos en 41 circuitos y 64 sub circuitos (barrios o comunidades), coordinando en forma conjunta tanto la Policía Nacional, la Fiscalía y la Judicatura. (Sub zona 18 de Policía Nacional de Tungurahua)

En el Código Orgánico Integral Penal - COIP, se menciona en la sección novena a los delitos contra el derecho a la propiedad como la extorsión, estafa, robo, hurto, entre otros. Es importante hacer una diferenciación entre la definición de hurto y robo.
Tabla 1. Diferencia entre hurto y robo

\begin{tabular}{|l|}
\hline \multicolumn{1}{|c|}{ Hurto } \\
$\begin{array}{l}\text { La persona que sin ejercer violencia, amenaza o intimidación en la persona o fuerza } \\
\text { en las cosas, se apodere ilegítimamente de cosa mueble ajena. Artículo } 189\end{array}$ \\
\hline Robo \\
$\begin{array}{l}\text { La persona que mediante amenazas o violencias sustraiga o se apodere de cosa } \\
\text { mueble ajena, sea que la violencia tenga lugar antes del acto para facilitarlo, en el } \\
\text { momento de cometerlo o después de cometido para procurar impunidad. Artículo } \\
189\end{array}$ \\
\hline $\begin{array}{l}\text { Fuente: Código Orgánico Integral Penal - CoIP } \\
\text { Elaboración: Ing. Jorge Tamayo, Ab. Ramiro Tite }\end{array}$ \\
\hline
\end{tabular}

\section{Contenido}

En relación a los delitos que se cometen contra la propiedad sin que se produzca violencia, se puede mencionar la existencia de 541 casos para el año 2012, evidenciándose un incremento del $40 \%$ en el 2013, se registran 987 y 1.052 denuncias de delitos en los años 2014 y 2015 respectivamente, apreciándose una disminución del 68\% en los delitos de hurto para el año 2016.

\section{Figura 1. Delitos de hurto en Tungurahua Periodo: 2012 - 2016*}

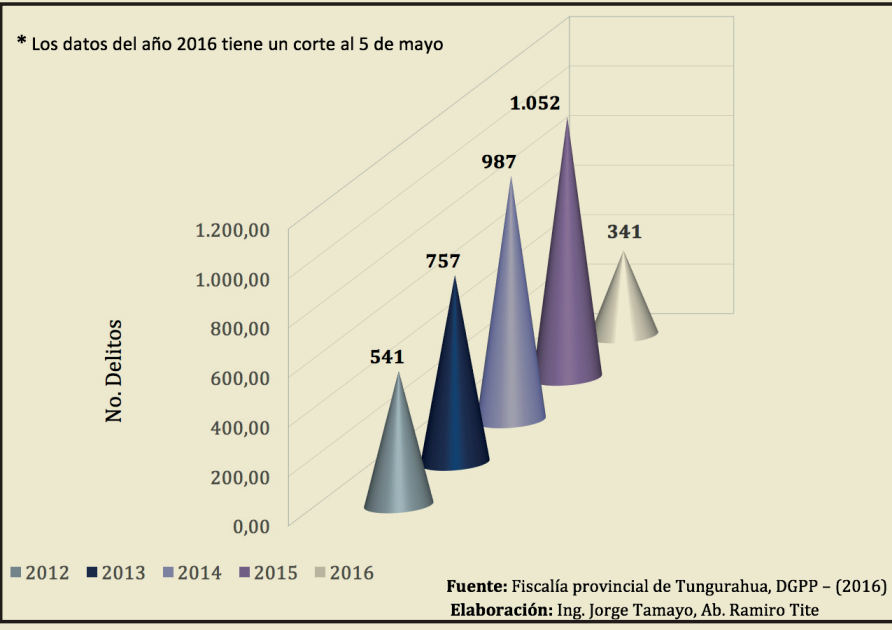

En el año 2012 se registraron la mayor cantidad de delitos de robo contra la propiedad con un total de 2.028 casos en la provincia de Tungurahua, disminuyendo en 15\% y 49\% para el año 2013 y 2014 respectivamente. Se registran 593 delitos en el año 2015 y una reducción del 64\% para el año 2016.

IIngeniero en Empresas - Docente investigador Facultad de Jurisprudencia y Ciencias Sociales UTA

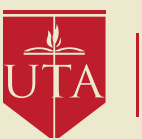

UNIVERSIDAD TÉCNICA DE AMBATO 


\section{Figura 2. Delitos de robo en Tungurahua Periodo: 2012 - 2016*}

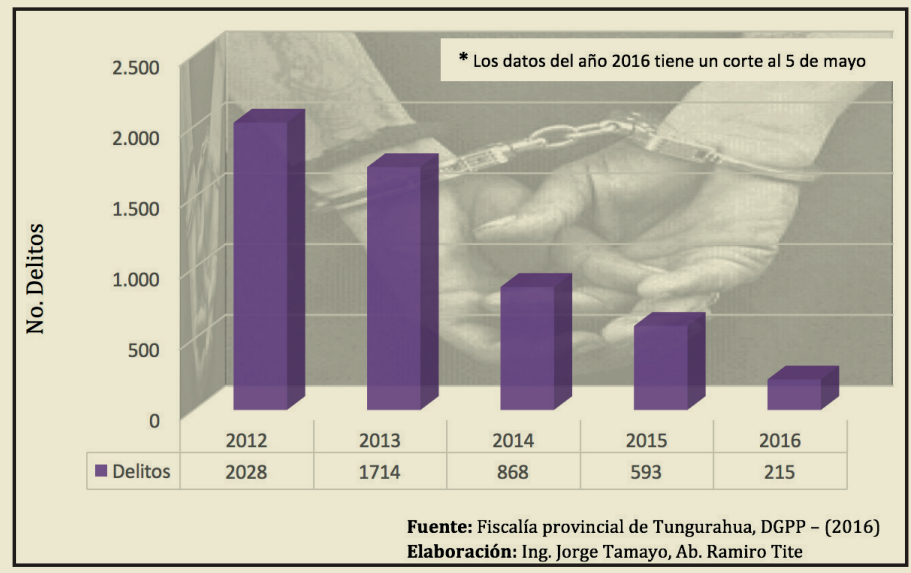

Del periodo comprendido de enero a junio de 2016, existe un incremento del $8 \%$ en delitos de robo a carros, $19 \%$ en robo a motos, $4 \%$ en robo a personas y $9 \%$ en robos a empresas. En relación a los delitos de robo de bienes, accesorios y autopartes de vehículos y los delitos de robo a domicilio presentan un decremento del $6 \%$ y $10 \%$ respectivamente. Se registra 1 delito de robo en ejes viales o carreteras en el mes de abril.

\section{Figura 3. Delitos contra la propiedad por tipo de afectados Periodo: enero - junio 2016}

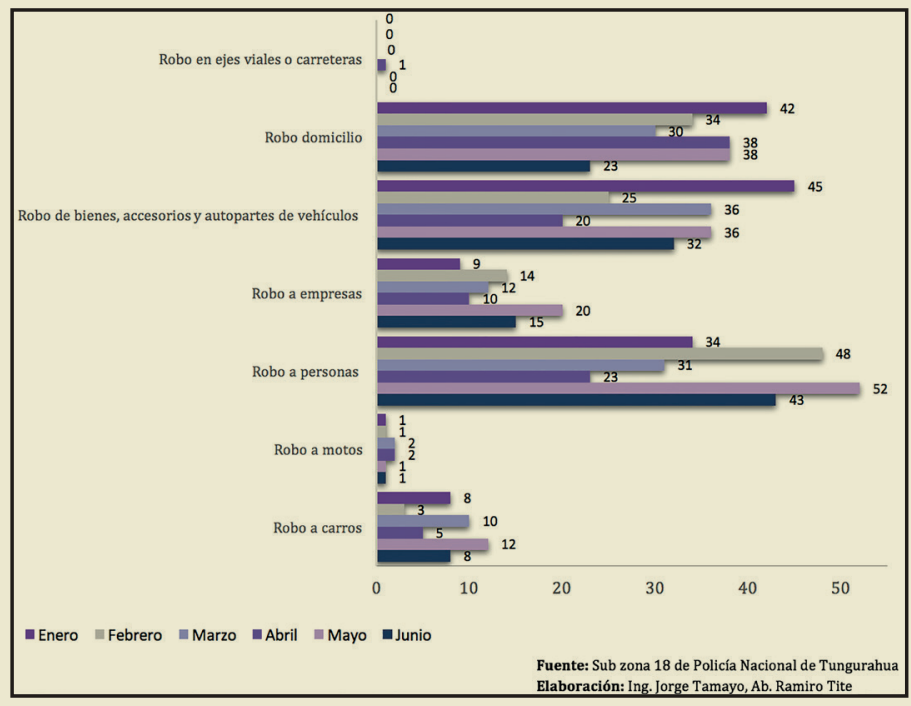

De lo que va del primer semestre del año 2016, se puede determinar que, en la noche se cometen la mayor cantidad de delitos contra la propiedad registrándose 227 casos entre robo a carros, motos, a personas, a empresas, bienes, accesorios y autopartes de vehículos y domicilios. En un segundo lugar se contabilizan 199 delitos contra la propiedad en la mañana y 199 en la tarde. Se presentan 141 casos de delitos contra la propiedad durante la madrugada.

\section{Figura 4. Horarios de los delitos contra la propiedad Periodo: enero - junio 2016}
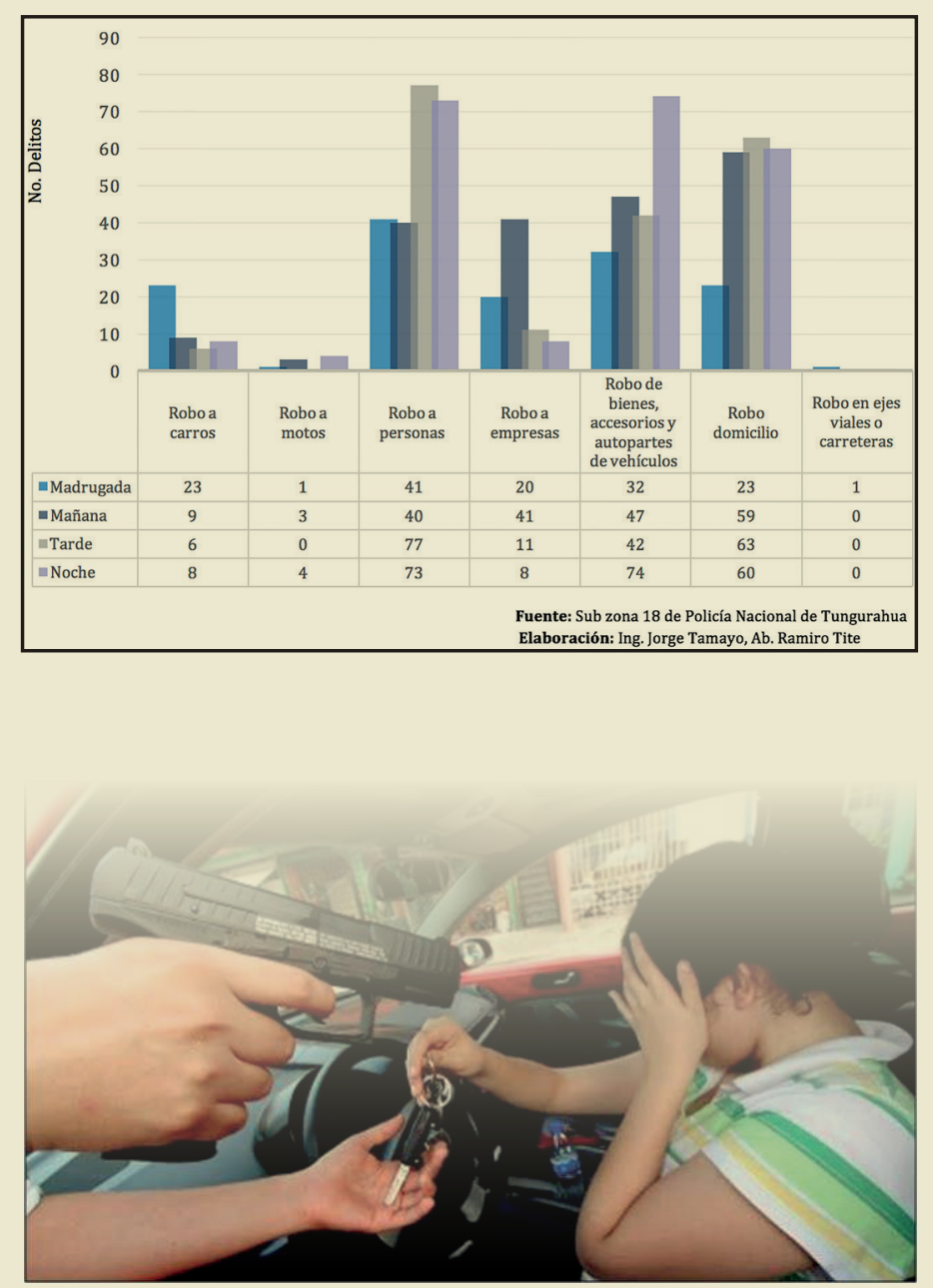

\section{REFERENCIAS}

-Código Orgánico Integral Penal (2015). Sección Novena. Delitos contra el derecho a la propiedad. Art. 185 - 208. págs. 31-34. Disponible en: http://www.asambleanacional.gob.ec/es/system/files/ document.pdf

- Facultad Latinoamericana de Ciencias Sociales (2008). "Programa Estudios de la Ciudad". págs. 4-9. Disponible en:http:// repositorio.flacsoandes. edu.ec/bitstream/10469/2294/1/BFLACSO-CS28-04-Esp\%C3\%ADn.pdf

-Fiscalía General del Estado (2016). Fiscalía Provincial de Tungurahua. Dirección Gestión Procesal Penal.

-Policía Nacional del Ecuador (2016). Sub zona 18 de Policía Nacional de Tungurahua. Unidad de Estadísticas.

- Universidad Técnica de Ambato (2016). Facultad de Jurisprudencia y Ciencias Sociales. Clínicas Jurídicas. 